\title{
ENTRE A CARIDADE, A DIVERSÃO E O MEDO: o dia de Cosme e Damião em uma vila do subúrbio carioca
}

Lucas Bártolo ${ }^{1}$

\section{Resumo}

Na cidade do Rio de Janeiro, a cada 27 de setembro, os santos Cosme e Damião são festejados, especialmente por devotos católicos e adeptos de religiões afro-brasileiras, com a distribuição de doces e brinquedos a milhares de crianças que saem às ruas nesse dia em busca das prendas. Neste artigo, apresento uma etnografia do dia 27 de setembro no Bairrinho, uma vila do subúrbio carioca onde vigoram fortes laços de parentesco e vizinhança; e há grande preocupação com a segurança, entendida a partir das relações com o mundo externo. Atentando ao caráter extraordinário desse dia, o qual reconfigura as dinâmicas sócio-espaciais da vila e promove a relação entre moradores e gente de fora, veremos como a festa de Cosme e Damião se realiza entre a caridade, a diversão e o medo.

Palavras-chave: Rio de Janeiro; Cosme e Damião; Sociabilidade; Casa; Rua.

\begin{abstract}
In the city of Rio de Janeiro, every September 27, Saints Cosmas and Damian, are celebrated, especially by devout Catholics and adherents of Afro-Brazilian religions, with the distribution of candies and toys to thousands of children who take the streets that day in search of gifts. In this article, I present an ethnography of September 27 in Bairrinho, a village in the suburbs of Rio de Janeiro, where strong ties of kinship and neighborhood are in place with great concern for security, which can be understood from relations with the outside world. Attempting to the extraordinary character of that day, which reconfigures the socio-spatial dynamics of the village and promotes the relationship between residents and outsiders, we will see how the feast of saints Cosmas and Damian ocurres between charity, amusement and fear.
\end{abstract}

Key Words: Rio de Janeiro; Cosmas and Damian; Sociability; House; Street.

\footnotetext{
${ }^{1}$ Mestre pelo Programa de Pós-graduação em Antropologia Social do Museu Nacional/UFRJ, onde atualmente cursa o doutorado. Possui graduação em Ciências Sociais pela Universidade Federal do Rio de Janeiro (2015). É membro do GPAD - Grupo de Pesquisa em Antropologia da Devoção e do Ludens - Laboratório de Antropologia do Lúdico e do Sagrado, ambos do PPGAS/MN/UFRJ.
} 


\section{Introdução}

No Rio de Janeiro, a devoção aos santos Cosme e Damião tem a sua principal expressão na festa do dia 27 de setembro ${ }^{2}$. Nesta data, milhares de crianças percorrem as ruas e bairros do Rio e Grande Rio em busca dos doces e brinquedos distribuídos em homenagem aos santos, principalmente por adeptos do catolicismo e das religiões afro-brasileiras. As crianças correm atrás de doce $e^{3}$ em grupos constituídos por vizinhos, colegas de escola e/ou parentes; e podem estar sob a supervisão de pelo menos um adulto ou adolescente mais velho que os acompanham. Os grupos transitam por ruas, praças, casas, vilas, igrejas católicas, terreiros de umbanda e candomblé, entre outros espaços nos quais a data é festejada. Nesse deslocamento, as crianças percorrem áreas da cidade que não frequentam rotineiramente, classificando os lugares como fortes ou fracos a partir da quantidade de saquinhos e da qualidade dos doces que conseguem pegar (MENEZES, 2013).

Este artigo tem por objetivo apresentar a festa dos santos Cosme e Damião ${ }^{4}$ em uma vila do bairro de Vista Alegre, subúrbio do Rio de Janeiro. Para tanto, nos debruçaremos sobre o material etnográfico produzido durante o trabalho de campo que realizei em 27 de setembro de $2013^{5}$, enquanto membro do projeto Doces Santos ${ }^{6}$. Inicialmente, apresentarei o Bairrinho, uma vila onde vigoram fortes laços de parentesco e vizinhança; e há uma constante preocupação com a segurança, entendida a partir das relações com o mundo externo - a rua -, mediadas pelas categorias morador e gente de fora, fundamentais para compreensão da festa naquele

\footnotetext{
${ }^{2}$ Originalmente estabelecida pelo calendário litúrgico católico - que depois alterou o dia dos santos para 26 de setembro -, a data permanece consagrada na tradição popular como o dia de Cosme e Damião.

${ }^{3}$ Ao longo do texto, os grifos em itálico, além de apontar os vocábulos estrangeiros, ressaltam as categorias próprias do universo pesquisado.

${ }^{4}$ Sobre o culto e festividades aos santos, ver: AUTOR, 2018; Carvalho, 1928; Cascudo, 1999; Frade, 1978; Freitas, 2015; Landes, 2002; Lima, 2004; Lopes, 2012; Menezes, 2016.

${ }^{5}$ Embora as primeiras reflexões acerca desse material tenham sido expostas em comunicação oral durante a Jornada de Iniciação Científica da UFRJ em 2014, o presente trabalho desdobra as questões apontadas naquele momento a partir de ferramentas analíticas adquiridas e exercitadas em meu mestrado, especialmente na Oficina de Pesquisa em Antropologia, ministrada pelos professores Moacir Palmeira e Renata Menezes, minha orientadora, no Programa de Pós-graduação em Antropologia Social da Universidade Federal do Rio de Janeiro. Agradeço às colegas Morenas Freitas, Débora Simões e Lívia Reis pelas ricas discussões ao longo da oficina, durante o primeiro semestre de 2016.

${ }^{6}$ Trata-se de uma pesquisa coletiva sobre a devoção em torno dos santos Cosme e Damião no Rio de Janeiro com foco nas dimensões da reciprocidade, das relações interreligiosas e dos fluxos urbanos articulados pela celebração dos santos gêmeos (MENEZES, 2013). O projeto é coordenado pela professora Renata de Castro Menezes e desenvolvido no âmbito do Grupo de Pesquisa em Antropologia da Devoção (Museu Nacional/UFRJ), sob o financiamento da FAPERJ. Cerca de vinte pesquisadores de diferentes níveis de formação colaboraram ao longo dessa pesquisa, que possui uma equipe permanente formada pela coordenadora Renata Menezes, por Morena Freitas (Doutoranda PPGAS/MN/UFRJ) e por mim.
} 
lugar. Para melhor compreender a relação que se dá entre a vila e a rua, utilizaremos como instrumento analítico as formulações de Roberto Da Matta (1997a) sobre o binômio casa/rua.

Veremos que no Bairrinho há um temor muito grande por parte de seus moradores quanto à presença de desconhecidos vindos da rua, trazendo consigo todos os perigos que lhes são atribuídos. No dia de Cosme e Damião, quando a rotina da vila é quebrada e essas pessoas desconhecidas vão até o Bairrinho em buscas dos doces que são distribuídos em homenagem aos santos, as relações evitadas ao longo do ano se evidenciam. E a festa entre moradores e gente de fora transita entre a caridade, a diversão e o medo. Assim, após expor como se configuraram as práticas ao longo desse dia na vila, nos debruçaremos sobre aquelas três dimensões que constituem a festa de Cosme e Damião nesse lugar. Por fim, pretendo refletir sobre a minha dupla posição, a de morador e pesquisador, pontuando as influências que essa ambiguidade teve durante a realização deste trabalho.

\section{Bairrinho}

Considerado por nossos interlocutores um local forte da festa de Cosme e Damião, o bairro de Vista Alegre, no subúrbio carioca, integra o trajeto de muitos grupos de crianças que correm atrás de doce, oriundos de áreas diversas da região metropolitana do Rio de Janeiro. Não é sem razão que os bolsistas de ensino médio, que integravam o projeto conosco e foram a campo no bairro da Pavuna, terminaram a jornada em Vista Alegre após seguir o movimento de alguns grupos naquele dia. No mapa abaixo, vemos ao centro a delimitação da área de Vista Alegre, enquanto as linhas vermelhas indicam os bairros vizinhos de onde partiram as crianças que encontrei em campo ${ }^{7}$. O mapa evidencia a relevância de Vista Alegre no circuito da festa, quando o bairro recebe, ao longo do dia, grupos vindos de diferentes locais do subúrbio em busca dos saquinhos distribuídos por lá.

\footnotetext{
${ }^{7}$ No âmbito do projeto Doces Santos, entre outras áreas da cidade, realizamos trabalho de campo em parte dos bairros indicados no mapa, como Pavuna, Irajá, Colégio, Brás de Pina, Vila da Penha e Penha.

${ }^{8}$ Com base em dados do Instituto Pereira Passos e da Fundação Getúlio Vargas, Freitas (2015) aponta uma clivagem econômica entre Vista Alegre e o entorno, uma vez que seus moradores pertencem às classes C e D, enquanto os residentes de bairros vizinhos flutuam entre as classes D e E. Freitas (Ibid, p. 59) ainda sugere que o protagonismo do bairro na realização da festa está relacionado a essa clivagem, uma vez que "os moradores dos bairros vizinhos vão até Vista Alegre e, mais precisamente, atravessam as cancelas do Bairrinho, porque lá os moradores [segundo uma criança ouvida na pesquisa] são 'ricos, que dão saquinhos bons'”.
} 


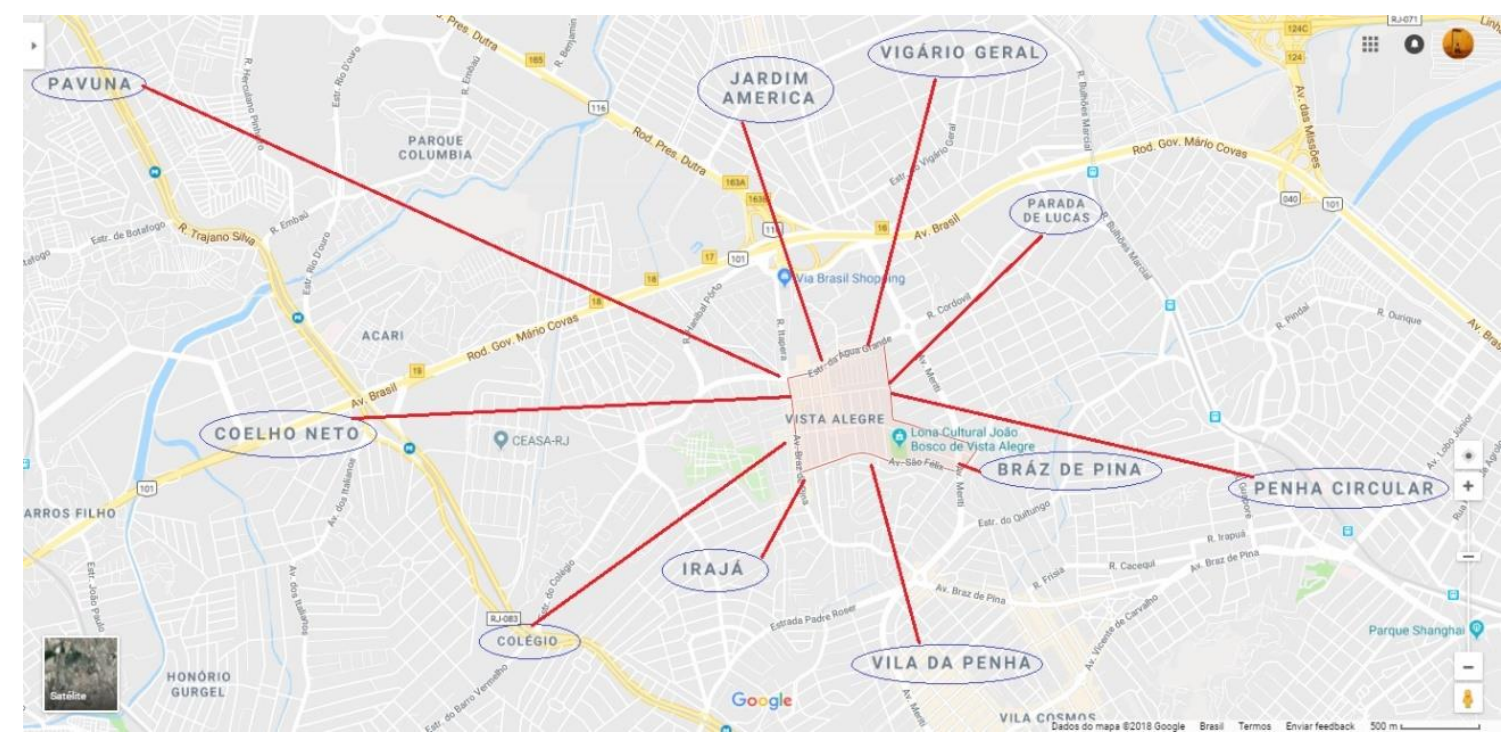

Fig 1: Área de Vista Alegre, localidade popularmente conhecida como Bairrinho.

Fonte: Google Maps, 2018.

O bairro ${ }^{9}$ teve sua origem na década de 1950 a partir de um empreendimento imobiliário de 400 casas, originalmente chamado de Jardim Vista Alegre, onde minha família reside desde sua criação. Na medida em que o bairro se expandiu, o local passou a ser popularmente conhecido como Bairrinho, sendo constantemente referido pelos moradores da região enquanto um condomínio, embora juridicamente seja reconhecido apenas como uma vila, sob os cuidados de uma associação de moradores, a AMOVILA. Como ilustrado no croqui abaixo, o Bairrinho consiste em três vilas integradas, constituídas por quatrocentas casas, onze ruas, cinco praças e uma quadra de esportes, além de uma sede da associação. Cada uma das três entradas do Bairrinho, todas com portão de ferro e cancela, é vigiada 24 horas por câmeras e porteiros.

Os porteiros são chamados de seguranças e sua função, em suma, é monitorar a entrada e saída de pessoas. Ao invés de fardas e armas, vestem-se com uniforme e pranchetas, nas quais registram os veículos que chegam ao Bairrinho. A suspensão dos serviços da portaria, uma ameaça constante por causa da inadimplência dos residentes às taxas cobradas pela associação, levaria à abertura dos portões, rompendo com as barreiras físicas que separam a vila e o mundo externo, expondo-a aos problemas e perigos que caracterizam o lado de fora.

\footnotetext{
${ }^{9}$ Vista Alegre pode ser considerado um bairro pequeno tanto por sua área de 51,52 hectares quanto por ter apenas 8.662 mil habitantes, dados que contrastam com os de Irajá, bairro ao qual pertencia oficialmente até a década de 1980, que possui 747,78 hectares de área e 96.382 mil habitantes. Fonte: http://populacao.net.br/ e http://www.bairrovistaalegrerj.xpg.com.br/, acesso em abril, 2018.
} 


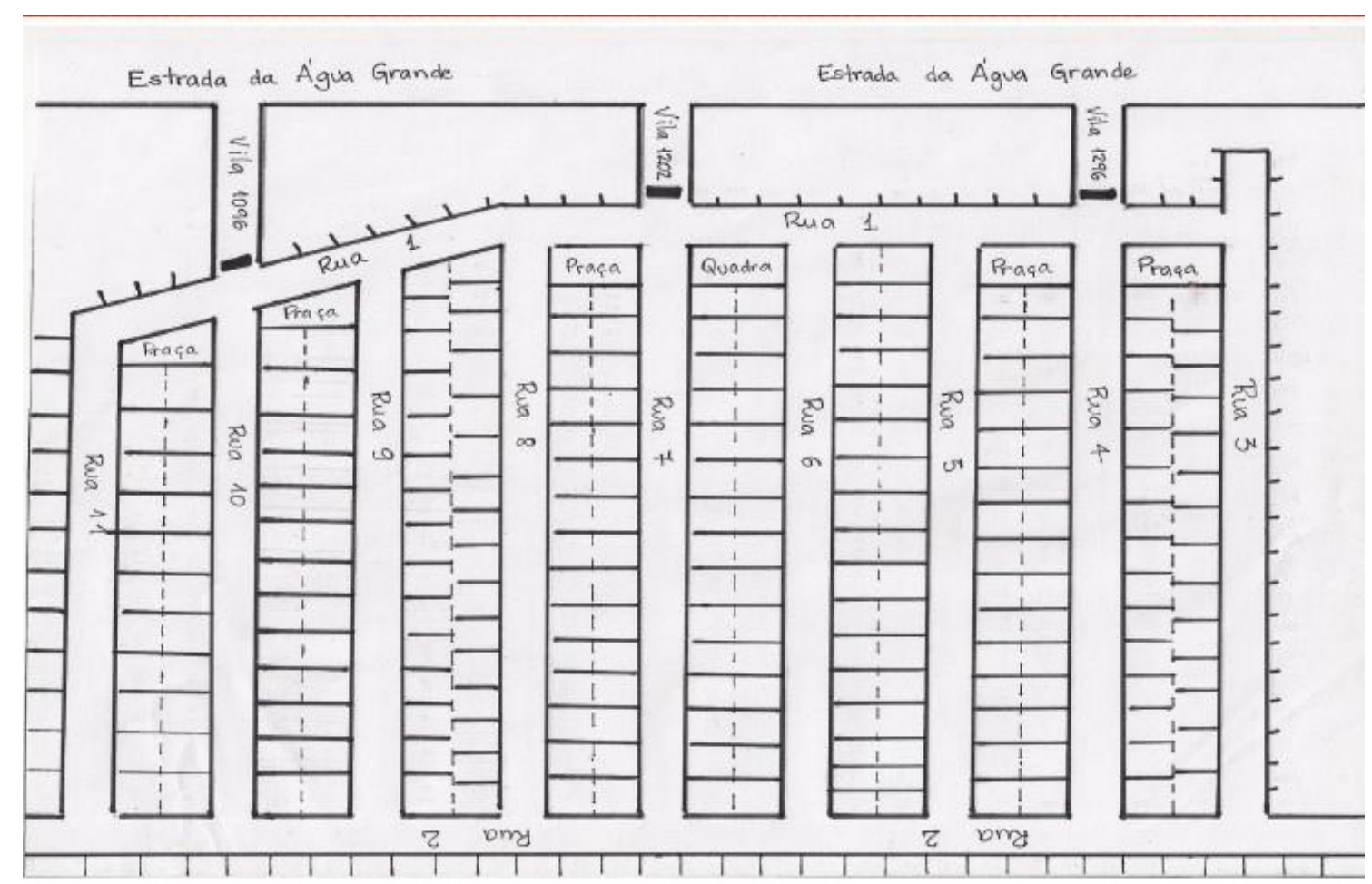

Fig 2: Croqui do Bairrinho.

Fonte: Morena Freitas, 2015.

Tal segurança é bastante prezada pelos que lá residem, sendo um dos fatores pelos quais a vila é considerada por eles um dos poucos lugares ainda habitáveis na cidade, portadora de uma realidade diferente da que se vê no lado de fora, como ouvi de alguns interlocutores durante a pesquisa. Essas ideias correspondem ao que nos mostrou Dionísio (2011) em trabalho sobre o sentimento topofilico - ou a afetividade que um indivíduo tem por um lugar - no mesmo Bairrinho. Atenta às relações sociais, aos aspectos imateriais e às diferenciações espaciais que atuam na afetividade das pessoas com o lugar em que vivem, a autora destaca a tranquilidade e o ambiente familiar como elementos fundamentais citados pelos moradores. Segundo Dionísio, a própria morfologia da vila favorece a construção de elos afetivos entre os moradores, que destacam também a sensação de segurança como fator unânime na escolha por residir no Bairrinho.

Enquanto esferas de sentidos, valores e moralidades, o Bairrinho e a rua parecem se adequar às formulações de Roberto Da Matta (1997a) sobre o binarismo casa/rua, códigos que 
organizariam a vida urbana brasileira ${ }^{10}$. Na casa, não há indivíduos, todos são pessoas e "se relacionam entre si por meio de laços de sangue, idade, sexo e vínculos de hospitalidade e simpatia" (MATTA, 1997a, p. 49); por outro lado, a rua é um espaço perigoso e marcado pela impessoalidade, "propício a desgraças e roubos, local onde as pessoas podem ser confundidas com indigentes e tomadas pelo que não são" (Ibid, p. 54)

Contudo, não lanço mão desses termos binários como conceitos explicativos, mas como instrumentos analíticos, na medida em que nos permitam acessar a dinâmica das relações sociais estabelecidas em determinados espaços; portanto, não tomarei essas categorias enquanto distinções absolutas. Matta (Ibid, p. 51) já havia chamado atenção para os espaços arruados da casa e os espaços de moradia da rua. E, como Mello e Vogel (1983) nos mostraram, há uma gradação nessa oposição, de modo que a dicotomia se reproduz em diferentes escalas, tanto no próprio espaço da casa, quanto no espaço da rua. Para esses autores, são as atividades praticadas nesse espaço que produzem os valores que são caros à comunidade e "os significados que determinados suportes materiais (esquinas, calçadas, soleiras etc.) assumem são o resultado de sua conjugação com certas atividades" (Ibid, p. 73). No Bairrinho, por exemplo, é comum que em ocasiões festivas o espaço fechado da vila ganhe delimitações ainda mais restritas, pois grupos de familiares e vizinhos fecham algumas ruas internas e praças para realizar suas festas. Em dias de calor, alguns moradores se reúnem em conversas de fim de tarde, dispondo em suas calçadas cadeiras que trazem de casa. À noite, no entanto, as ruas internas vazias e pouco iluminadas parecem permeadas pelo caráter arruado que ameaça o clima de domesticidade.

Nesse sentido, embora sejam importantes na circunscrição física do espaço, as portarias sob os cuidados dos porteiros não são as únicas responsáveis pela sensação de segurança dos moradores, pois não é apenas a demarcação física que instaura nas onze ruas da vila um universo majoritariamente codificado pelo mundo doméstico. Apenas pelas grades, ao invés da familiaridade e amizade, poderiam prevalecer o individualismo e a impessoalidade. Esse papel

\footnotetext{
${ }^{10}$ Embora as definições de Matta sobre esse binômio tenham sido ferramentas importantes para compreendermos as categorias que encontramos em campo, reconheço que são carregadas de uma moralidade excessivamente burguesa. A exemplo de outras formas de conceber essa relação, o trabalho de Velloso (1990), sobre espaço e identidade cultural no Rio de Janeiro do início do séc. XX, nos mostra que enquanto na delimitação do espaço da mulher burguesa a rua era moralmente desqualificada em contraponto à idealização da casa, as negras quitandeiras encontravam nas ruas o espaço fundamental de liberdade de iniciativa, resistência e poder. Pela perspectiva das mulheres de camadas populares, portanto, a rua adquire um caráter positivo, onde a sociabilidade e os laços sociais eram criados e reforçados.
} 
deve ser atribuído às relações sociais estabelecidas naquele espaço sob a lógica da boa vizinhança e parentesco. Essas relações fazem da vila um espaço de afetividade, amizade e familiaridade em contraponto ao impessoal, perigoso e desconhecido espaço da rua.

Esses dois códigos de significação social - o Bairrinho e a rua - correspondem a duas categorias utilizadas na vila para organizar as relações entre os dois mundos, sobretudo em situações críticas, quando há a ameaçadora presença de um estranho: morador e gente de fora. Contudo, não são categorias que estabelecem distinções absolutas, pois, como já vimos, o próprio espaço da vila não pode ser cristalizado em um só domínio. Tais categorias são relacionais, acionadas situacionalmente uma em contraponto a outra. Elas não estão submetidas ao legalismo que apenas identificaria quem reside ou não no Bairrinho, pois morador não é necessariamente uma pessoa que mora na vila.

Como apontei acima, um desconhecido é potencialmente portador dos perigos da rua, de onde veio. Mas, uma vez identificado, exceto se for um eventual prestador de serviços, é inserido no universo das relações pessoais na medida em que deixa de ser um anônimo para tornar-se um conhecido. Desde um assíduo frequentador da vila até um visitante de primeira viagem podem ser considerados moradores se estiverem vinculados aos laços de parentesco, vizinhança ou amizade na vila. Essas pessoas apenas têm o status ameaçado quando seus interesses são contrários aos dos efetivos moradores, em possíveis desentendimentos nos quais os proprietários podem acionar as categorias de fora e morador em sua dimensão mais legalista - o que quase sempre é em vão, pela força das relações pessoais e de boa vizinhança que se sobrepõem a esses argumentos de propriedade.

No início da década de 1980, os já referidos Mello e Vogel (1981) chamavam atenção para as mudanças nos projetos de habitação na cidade do Rio de Janeiro, apontando a tentativa de instituição de um modelo de vida urbano positivista que pautava a impessoalidade e institucionalização, calcados na primazia da individualidade moderna, em detrimento dos tradicionais laços comunitários, da diversidade e negociações dos usos e significados. A partir do trabalho etnográfico, em que adotaram uma visão processual e dinâmica para pensar o espaço, os autores questionaram a eficiência desses modelos de vida urbana ao mostrar que, mesmos projetos excessivamente racionalistas, onde vigora uma ordem única que segrega e disciplina os espaços, podem ser subvertidos ou complexificados pelas formas de apropriação e os múltiplos usos que o caracterizarão. 
No Bairrinho, vemos a força dos valores comunitários sustentada, sobretudo, pelos duradouros vínculos afetivos estabelecidos há pelo menos três gerações, os quais se estendem por todo o bairro de Vista Alegre. Valores tradicionais que ainda prevalecem sobre os princípios de institucionalização, anonimato e individualidade que acompanham o crescimento da opção das camadas médias brasileiras pelos condomínios horizontais murados e com forte aparato de segurança (MOURA, 2003). Assim, enquanto o investimento na segurança da vila ganha força e as casas ganham muros cada vez mais altos, os moradores se associam em diferentes níveis de intimidade e os usos das praças e da quadra esportiva, por exemplo, seguem acordos informais, ambíguos e instáveis. Nesse sentido, compreendemos a importância dessas categorias - morador e de fora - nas negociações e interações que marcam a sociabilidade da vila, o que se evidencia na forma pela qual o dia de Cosme e Damião é celebrado nesse lugar.

\section{O dia de São Cosme e Damião no Bairrinho"}

O dia de Cosme e Damião instaura outra temporalidade, alterando a dinâmica das relações sócio-espaciais do Bairrinho. No dia 27 de setembro não é ocasião de escancarar os portões de veículos e o serviço de portaria permanece identificando os motoristas que entram na vila. Os pedestres, porém, como nos outros dias do ano, salvo excepcionalidades, entram livremente. O ponto é que, cotidianamente, pessoas alheias aos moradores não transitam por aquele espaço. Em dias corriqueiros, as centenas de pessoas que entram na vila no Cosme e Damião não passariam sem antes causar espanto e terror aos moradores e ao próprio porteiro, que no dia 27/09 assiste passivo à entrada desses grupos.

Ao longo de todo o dia, os grupos de crianças, de fora e moradoras, correm as ruas em busca dos doces distribuídos na vila em homenagem aos santos. Há diversas modalidades de dar doce. Nos portões de suas casas, os devotos entregam às crianças os saquinhos, feitos de papel ou de plástico, estampados com a imagem dos santos e cheios de guloseimas, dentre as quais podemos listar uma infinidade de qualidades: suspiro, pipoca, bananada, doce de leite, doce de abóbora, chocolate, bala, pirulito, cocada, maria-mole, cocô de rato, peitinho de moça, pé-de-moleque, pé-de-moça, jujuba, chocolate em formatos diversos (guarda-chuvinhas,

\footnotetext{
${ }^{11}$ A dissertação de Morena Freitas (2015), defendida no âmbito do projeto Doces Santos, apresenta uma fina etnografia da festa de Cosme e Damião no Bairrinho pela perspectiva das crianças que a pesquisadora acompanhou ao longo do dia 27/09 no ano de 2014. Alguns aspectos aqui mencionados - e outros tantos que ficaram fora do alcance deste trabalho - são aprofundados e analisados nessa dissertação.
} 
moedas, bolinhas de futebol) etc. Além dos saquinhos, também são distribuídos brinquedos como bolas de futebol, pipas e bonecas, o que acompanha uma divisão de gênero entre brinquedos de menino e de menina. As distribuições de doces e brinquedos também podem ser feitas de carro ou a pé, quando o doador buscar por lugares estratégicos para fazer a sua distribuição, como as praças que concentram grupos de crianças. Lembremos ainda das igrejas dos santos Cosme e Damião existentes na cidade onde há festas e distribuição

Outra modalidade é dar uma mesa, como se fosse uma festa de aniversário, comemorando o dia 27 de setembro com bolo e doces - não apenas os dos saquinhos, mas principalmente os chamados doces de mesa, os quais se come de colher: manjar, pudim e doce de abóbora, por exemplo. Para participar dessa festa, as crianças entram na sala, copa ou garagem dos devotos, onde está montada a festa e, após cantar parabéns para os santos, recebem os quitutes.

$\mathrm{Na}$ vila, entre as oito e nove horas da manhã, o som dos primeiros chinelos estalando em correria pelas ruas anuncia o começo de mais um dia de São Cosme e São Damião. Mas o movimento de pessoas em torno da festa ainda é tímido no início do dia, o que se nota pelo silêncio nas ruas majoritariamente vazias, quebrado pelas poucas crianças que passam correndo ao sinal de um ou outro doce. A vila recebe pela manhã a visita de pequenos grupos constituídos por crianças, que aparentam não mais que cinco anos de idade, acompanhadas dos pais. O clima familiar é predominante, proporcionando cenas que dificilmente veremos ao longo do dia, como um pai fotografando o filho com os doces ou a família reunida acompanhando a criança: pai, mãe e avó.

Nesse início, os únicos grupos de crianças que percorrem as ruas sem os pais são de moradores, isto é, crianças que, se não residem na vila, são amigos ou parentes das que efetivamente moram, de modo que muitos vão para o Bairrinho ainda na véspera, dormindo na casa de seus colegas e familiares. Esses grupos se reconfiguram, desmantelam e são refeitos ao longo do dia. Cerca de quinze garotos entre oito e treze anos integram esses grupos, que ora formam um único grupo, ora se distribuem em trios ou mesmo em duplas. Se reconfiguram na medida em que se reencontram pela vila: uns querem seguir por um caminho, outros preferem ficar pelas praças; alguns param em casa e quando retornam se unem ao outro grupo. Caminham juntos pelas ruas internas, dividem e trocam os doces que não gostam, mas competem entre si 
e com todos na hora de pegar os saquinhos. É também um auto desafio para conseguir pegar mais doces do que nos anos anteriores.

Ao menor sinal de distribuição de doce, às vezes um boato, disparam na direção apontada e nessas horas é cada um por si para chegar primeiro até o portão da casa em que estão distribuindo os saquinhos de doce ou fazendo a fila para a festa de mesa. Na hora de pegar os saquinhos, apesar do caráter competitivo que marca esse momento, algumas crianças pedem os doces para uma irmã ou um primo que não pôde estar lá naquele momento. Por vezes, pedir por alguém é também uma estratégia das crianças enganarem os adultos, conseguindo mais de um saquinho para si.

Com o passar da manhã, entre dez e onze horas, os diversos grupos vindos de fora começam a chegar à vila. Perde-se a calmaria e o fluxo de pessoas torna-se constante com centenas delas percorrendo as onze ruas do Bairrinho. Os grupos de crianças agora competem pelos saquinhos com os grupos de desconhecidos e a disputa se dá também por ameaças, agressões verbais e até brigas corporais. Quando conversei com um grupo de moradores entre dez e treze anos de idade, eles contaram que alguns garotos de fora, mais velhos, em torno dos quinze anos de idade, abriram a mochila de um dos moradores e furtaram alguns saquinhos. Ainda segundo os meninos, os rapazes tentam arrumar confusão ao longo de todo o dia, pois os encaram e provocam cada vez que se cruzam pelas ruas. Os meninos me relataram uma briga durante a festa, quando à tarde o movimento de doces não estava bom e os meninos da vila jogavam bola. Os rapazes de fora tentaram se impor no futebol dos meninos e o porteiro precisou intervir, fechando a quadra de esportes para todos.

Seguindo a ideia de que há uma dimensão perigosa na vila durante o dia de Cosme e Damião, levada pelos desconhecidos de fora, podemos pensar que correr atrás de doces no Bairrinho constitui um rito de passagem para os grupos de moradores que, ao alcançar determinada idade, podem percorrer a vila neste dia sem os pais e até acompanhar as crianças mais novas. Apesar de certa autonomia, o espaço delimitado e as relações que lá predominam mantêm a criança, independentemente de sua idade, sob a supervisão dos adultos, que estão pelas ruas da vila ou debruçados em suas janelas ou portões. A maioria das crianças moradoras que correm atrás de doce sem os pais não pode atravessar os portões da vila expondo-se ao universo pleno do perigo e da vulnerabilidade, mas também faz parte da brincadeira o desafio 
de sair escondido para pegar doces em outros lugares. É provável que ao alcançarem essa permissão já tenham perdido o status de criança e deixado de correr atrás de doce ${ }^{12}$.

O espaço doméstico, da família e da boa vizinhança, que predomina na vila é separado da rua pelos portões gradeados e guardado por câmeras e porteiros. Com essa separação de mundos, vemos em ocasiões ordinárias ocorrer aquilo que Gennep (2013, p. 33) chamou de ritos de soleira, nos quais a passagem por marcos materiais acompanha a passagem de status social. Nesse sentido, compreendemos melhor a figura do porteiro como um segurança, pois se trata de um mediador na passagem entre os dois mundos, regulando o acesso e assegurando a delimitação dos espaços morais. Os que ultrapassam as fronteiras sem terem seus status convertidos, isto é, sem serem identificados como eventuais prestadores de serviços ou dentro dos laços de vizinhança, amizade e/ou parentesco, ameaçam à ordem vigente na vila por seu caráter liminar.

Aqui, falamos do perigo associado à liminaridade no sentido proposto por Turner ao desdobrar as ideias de Gennep acerca dos ritos de passagem, entendidos enquanto uma sequência constituída por etapas de separação, liminaridade e reagregação, refinando o entendimento sobre o estágio intermediário desse processo ritual. Embora um dos caminhos de sua teoria aponte para a ideia de communitas, que seria um estado anti-estrutural compartilhado pelos sujeitos que se encontram na margem, interessa-nos aqui os apontamentos de Turner acerca do caráter potencialmente ambíguo e perigoso atribuído ao estado liminar, que ameaça o sistema estável de posições e classificações sociais ${ }^{13}$. Ele nos diz:

\begin{abstract}
Os atributos de liminaridade, ou personae (pessoas) liminares são necessariamente ambíguos, uma vez que esta condição e estas pessoas furtam-se ou escapam à rede de classificação que normalmente determina localização de estados e posições num espaço cultural. As entidades liminares não se situam aqui nem lá, estão no meio e nas posições atribuídas e ordenadas pela lei, pelos costumes, tradições e cerimonial. Seus atributos ambíguos e indeterminados exprimem-se por uma rica variedade de símbolos, naquelas várias sociedades que ritualizam as transições sociais e culturais. Assim, a liminaridade frequentemente é comparada à morte, ao estar no útero, à invisibilidade, à escuridão, à bissexualidade, às regiões selvagens e a um eclipse do sol ou da lua (TURNER, 1974, p. 117).
\end{abstract}

\footnotetext{
${ }^{12}$ A ida à rua enquanto um rito de passagem já havia sido sinalizada por Roberto Da Matta: “[...] constitui um ritual muito importante e altamente sombrio a primeira vez que alguém (menino ou menina) vai para a rua sozinho, seguindo sua própria cabeça, acompanhando apenas as pessoas de sua idade, estando 'naturalmente' sujeitos a todos os perigos e tentações que recheiam aquele espaço" (MATTA, 1997a, p. 55).

${ }^{13}$ Aspecto também explorado nos trabalhos de Leach (1964) e Douglas (2012).
} 
Nesse sentido, podemos entender o perigo carregado pelos desconhecidos em estado de liminaridade, pois desafiam os esquemas classificatórios que organizam a vida no Bairrinho em códigos domésticos, permanecendo de fora desse mundo. Uma vez que a festa do dia 27 de setembro leva à suspensão dos limites materiais entre a vila e o mundo externo, os santos gêmeos poderiam ser celebrados na integração entre todos os participantes, superando não só as fronteiras físicas, mas também os status sociais - o que poderia nos levar a pensar a festa em termos de communitas (TURNER, 1974; MATTA, 1997b). No entanto, o que se vê não é uma celebração plenamente harmônica e homogênea. Embora proporcionada pelo caráter extraordinário desse dia, a presença de centenas de pessoas alheias à rotina da vila nesse espaço não é algo naturalizado. Pelo contrário, essa eventualidade parece ser vista pelos moradores tanto como uma ocasião festiva quanto uma vulnerabilidade crítica. Os desconhecidos vindos da rua são, em um só tempo, agentes fundamentais na realização da festa e ameaças à tão estimada sensação de segurança.

Para lidar com essa contiguidade espacial entre mundos, algumas categorias são acionadas pelas pessoas da vila para organizar essas relações sociais atípicas que constituem o dia de Cosme e Damião. Ao nos atermos a essas categorias, a festa de do dia 27 de setembro no Bairrinho aparece como um rito de instituição (BOURDIEU, 2008), uma vez que visibiliza e institui status sociais que são demarcados cotidianamente pelas grades e portões. Tratando-o como um ritual, podemos ver que o dia de Cosme e Damião na vila não supera as diferenças entre moradores e gente de fora ao reconfigurar a dinâmica sócio-espacial, mas acaba por evidencia-las e reforça-las nas práticas que constituem a festa. Sigamos, então, a sugestão de Bourdieu para atentarmos não à passagem ritual e às pessoas que têm seus status transformados, mas à separação e aos sujeitos que não podem ultrapassar as fronteiras. Se há uma divisão que fundamenta a ordem social, faremos o exercício de olhar para o ritual como um meio pelo qual as separações e diferenciações são instituídas e naturalizadas.

As grades, cancelas e porteiros, somados à predominância dos laços afetivos e de vizinhança, tornam o Bairrinho um espaço fechado a desconhecidos, de modo que não são frequentes situações críticas de visitantes indesejados, apesar da constante preocupação dos moradores. Nesse sentido, apesar da nítida separação espacial entre a vila e a rua através dessas fronteiras materiais, a demarcação social é invisibilizada, pois não sabemos exatamente de quem ela está sendo protegida, já que o isolamento consegue ser eficaz. 
É na festa de Cosme e Damião que os moradores se relacionam com aqueles de quem se protegem ao longo do ano e a pessoas de fora podem finalmente frequentar um espaço que lhes é restrito usualmente. Apesar da livre passagem, os desconhecidos não se inserem na lógica do mundo doméstico, permanecendo vinculadas à impessoalidade perigosa da rua. Com a suspensão da separação material entre os dois mundos, a sensação de segurança no Bairrinho é ameaçada e as fronteiras passam a ser demarcadas por determinadas categorias: moradores e gente de fora, favelado e coitado. A festa nos mostra as demarcações sociais que estão naturalizadas ou veladas no cotidiano e, ao invés de suspender essas diferenças, as reforça na medida em que as visibiliza.

\section{A caridade e o medo}

As pessoas de fora quando percorrem as ruas do Bairrinho atrás dos doces, sejam adultos com seus pequenos ou as crianças mais velhas sem os pais e em seus respectivos grupos, estão, a princípio, no estado liminar. Deles, os moradores nada sabem e associam essas pessoas aos aspectos que constituem o imaginário em torno da rua, inclusive a condição de précriminalidade. A impessoalidade dá margem para equivocadas formulações e acusações. Os moradores que dão doces definem os grupos de fora sem nenhuma precisão, utilizando, entre outras, duas categorias recorrentes: favelado e coitado, através das quais organizam boa parte das relações na festa.

Chamar alguém de favelado é uma forma de acusação generalizada na festa, pois não é utilizada apenas pelos moradores para classificar os desconhecidos de fora; os próprios membros de um grupo a utilizam entre si. Na festa, entre os grupos, o termo favelado é acionado quando alguém repreende o comportamento violento ou grosseiro daquele que grita, xinga ou bate nos colegas. Ouvi esses termos principalmente entre garotos de fora que percorriam as ruas da vila com brincadeiras violentas, batendo uns nos outros. Quando um dos rapazes se exaltava, um deles ordenava em tom jocoso: "deixa de ser favelado" ou "pare com isso, seu favelado". Pareciam mais preocupados em não levar bronca dos adultos da vila do que verdadeiramente incomodados com o comportamento do colega.

Pessoas que não eram moradoras também acionavam o termo favelado quando acusavam outros grupos de agressões e furtos. Aqui, o termo tem uma dupla qualificação, referindo-se não só ao mau comportamento, mas também à origem social dessas pessoas, 
supostamente vindas de áreas favelizadas da região. O exemplo do furto de saquinhos de doce ilustra como os próprios garotos de fora chamavam outros grupos de favelados, como vemos na fala de um rapaz ao comentar o episódio: "Tem muito favelado do Amarelinho ${ }^{14}$ arrumando confusão". É interessante ainda atentar para o fato de que, a princípio, o grupo que acusava é visto sem distinções pelos moradores em relação aos supostos favelados do Amarelinho. Para as pessoas da vila, todos são enquadrados como grupos de fora e, quase sempre, favelados e/ou coitados. Ressalta-se que esses grupos vindos de fora, em sua maioria, eram formados por crianças e adolescentes negros.

Com exceção das festas de mesa, os doces costumam ser distribuídos através dos portões das casas e os moradores tentam organizar as crianças em fila, distribuindo os saquinhos individualmente. Mas, em geral, um pequeno tumulto acontece diante da casa em que se distribuem os doces com a chegada das crianças eufóricas e não raro a situação pode fugir do controle do doador. Observei um desses casos naquela tarde de 2013, quando dezenas de crianças e os adultos que as acompanhavam faziam um grande tumulto em frente à casa de uma senhora que, em vão, pedia ordem e tranquilidade para entregar os doces. A confusão chegou ao ponto em que algumas pessoas subiram em um carro que estava estacionado no local para tentar pular o muro daquela casa e garantir o seu doce. No entanto, quanto mais a senhora se recusava a dar os doces enquanto não houvesse ordem, mais o tumulto aumentava. Com o fracasso dos seus apelos, a senhora decidiu jogar avanço os doces, atirando-os por sobre o muro para a pequena multidão que se formou na frente de sua casa. Saquinhos de Cosme e Damião e alguns doces avulsos eram atirados e disputados pelas dezenas de crianças aos empurrões e gritos, mas não houve brigas nesse momento.

É uma estratégia distribuir doces através dos portões de casa, para se proteger do alvoroço que toma conta das ruas. No entanto, algumas pessoas preferem entregar os saquinhos nas praças da vila para evitar algum dano em suas casas, como já ouvi relatos de portões que foram quebrados pelas crianças. Quando as situações se tornam críticas, como o episódio acima, deixa de ser a algazarra das crianças para ser desordem e falta de educação, relacionados

\footnotetext{
${ }^{14} \mathrm{O}$ Amarelinho é uma favela localizada no bairro de Acari, às margens da Avenida Brasil, surgida a partir de um conjunto habitacional do Instituto de Aposentadorias e Pensões dos Industriários (IAPI), cujos prédios possuem fachada amarela.
} 
principalmente à presença de desconhecidos e, nesses casos, o termo favelado é frequentemente utilizado.

Silva (2010), ao trazer algumas considerações sobre as representações em torno do subúrbio e da favela, nos mostra que ambas se aproximam pela incorporação da ideia de pobreza, abandono e precariedade. Mas enquanto o primeiro sofreu diversos raptos ideológicos (FERNANDES, 1995) ou mudanças de significados, a favela jamais livrou-se da representação estigmatizada do lugar do pobre, vagabundo e/ou bandido, mesmo quando também está vinculada a aspectos positivos. Na dinâmica da festa no Bairrinho, a categoria carrega essas representações negativas para acusar, inclusive, aqueles que não são moradores de favelas. As representações em torno da favela e da rua parecem se confundir pelas ideias da pobreza e da marginalidade, que vemos na festa na dupla dimensão da caridade e do medo.

Se, por um lado, favelado é uma categoria que nos fala de um dia festivo em que o medo é um sentimento predominante; por outro, vemos a festa de Cosme e Damião na vila como uma prática caridosa feita pelos moradores. Enquanto a primeira categoria denota a marginalidade e o perigo, os coitados trazem a dimensão menos ameaçadora da rua, a vulnerabilidade social. Aqui, podemos até identificar uma transição da ideia de favela para comunidade carente. Por essa perspectiva, os grupos de fora são vistos menos como mal-educados e violentos do que carentes social e afetivamente.

Como vimos, as distribuições de doce são feitas com certo cuidado para evitar o tumulto e violência atribuídos quase sempre aos favelados. Pela caridade, a estratégia de distribuição dos doces privilegia as crianças consideradas carentes pelos doadores, em uma escala de prioridades liderada pelas crianças mais novas e pelas meninas, além das gestantes. A atribuição do status de coitado parece estabelecer quem são aqueles que participam da festa apenas por uma via: a do receptor. Enquanto boa parte das crianças moradoras que correm atrás dos doces também fará a sua distribuição em algum momento do dia, aqueles que são considerados carentes estão privados dessa possibilidade. Pobres, essas pessoas não teriam condições econômicas para dar doces e, além disso, só encontrariam oportunidade de comê-los fartamente no dia de Cosme e Damião. Nisso, há um recorte racial e nota-se um padrão dos grupos que se enquadram nessa categoria privilegiada pelos doadores: costumam ser grupos liderados por jovens negras que trazem algumas crianças sob os seus cuidados e um carrinho de bebê precário em que são guardados os brinquedos e doces recebidos ao longo do dia. Na medida em que a 
caridade se constitui um fator central na realização da festa, vemos a substituição dos doces e brinquedos por refeições e cestas básicas.

Ao tratar do sistema de crenças do espiritismo, Cavalcanti (1983) nos mostra como a caridade se realiza tanto pela assistência aos que necessitam de ajuda material quanto pelo apoio moral aos desamparados e, ainda, como os pobres desempenham um papel específico nesse sistema simbólico. Representantes do mundo de expiações e imperfeições nos termos espíritas, os pobres trazem a marca da carência e da necessidade humana, o que, por outro lado, permite o aperfeiçoamento moral dos não-pobres pelo exercício da caridade. Essa lógica, portanto, demarca e hierarquiza aqueles que dão e os que recebem, sustentada pela estrutura desigual da sociedade. A doação daqueles que possuem ao pobre carente não supera essa diferença, mas a reforça.

Nesse sentido, as distribuições de doces no Bairrinho - embora realizada por adeptos de diversas religiões como o catolicismo, a umbanda e o kardecismo - podem ser compreendidas como práticas caridosas, na medida em que os moradores façam suas doações para suprir as necessidades materiais e afetivas das crianças e suas mães que correm atrás de doces. Na festa que permite a temida entrada de desconhecidos, a distribuição dos doces e outras prendas enquanto prática caridosa é uma das formas pelas quais se institui as diferenças entre moradores e gente de fora.

\section{A diversão}

Até aqui, vimos o dia de Cosme e Damião na vila como uma festa entre moradores e gente de fora, que se realiza pelo medo e pela caridade, evidenciadas pelo uso das categorias favelado e coitado. Há, no entanto, uma dimensão fundamental dessa festa que ainda não foi tratada aqui: a diversão. Embora não ocorra uma integração plenamente harmoniosa entre os participantes dessa festa, o que há no dia 27 de setembro é uma grande brincadeira que celebra os santos gêmeos. Se a diversão pode ser vista enquanto uma caridade que supre a falta de afeto, ela não se limita a essas prestações feitas aos coitados. E o próprio medo, causado pela presença de pessoas estranhas na vila, não impede que a festa seja divertida.

Para aqueles que dão doce, ver o sorriso das crianças, alegres ao receberem os saquinhos de Cosme e Damião, é uma das razões pela qual se faz a festa, mesmo que elas sejam frequentemente frustradas com xingamentos e ataques aos seus portões. Os grupos de crianças 
se divertem competindo quem pega mais doce e apostando quem chega primeiro à casa que está dando a prenda; além disso, brincam pelas ruas com as bolas, pipas e bonecas que também são entregues nesse dia.

Apesar desses divertimentos aparentemente ingênuos, mas fiéis ao imaginário de pureza associado às crianças, algumas brincadeiras que vi desviavam dessas virtudes. Mesmo que alguns comportamentos sejam reprovados pelos adultos que participam da festa, não podemos desconsiderar que a brincadeira também pode ser violenta e agressiva. Meninos e meninas, por exemplo, guerreavam com os doces ao invés de comê-los, atirando as guloseimas uns nos outros, como testemunhei em uma das praças da vila. Outros garotos enquanto percorriam as ruas à procura dos doces, brincavam de distribuir tapas e pontapés no primeiro colega que falasse ou fizesse alguma bobagem. A própria rivalidade e briga entre os grupos, chegando a acusações de furto, é parte dessa sociabilidade festiva e violenta.

Também vemos isso quando as prendas são jogadas avanço, atiradas à multidão, que avança sobre as balas espalhadas no chão. No caso que relatei anteriormente, essa prática foi o resultado do fracasso de uma distribuição mais organizada. Mas no dia de Cosme e Damião, jogar avanço é uma modalidade bastante popular e alguns doadores se notabilizam justamente por essa prática, distribuindo não só doces, mas também brinquedos e mesmo moedas. Aqui, a brincadeira está justamente no tumulto causado pelo avanço das pessoas competindo pelas prendas, gerando empurrões, puxões de cabelo e outras agressões. Muitas vezes as crianças ficam de fora dessa brincadeira e os adultos que as acompanham participam das disputas.

Portanto, a caridade, a diversão e o medo podem ser considerados como diferentes dimensões pelas quai o dia de Cosme e Damião é vivido no Bairrinho e que não são absolutamente excludentes. Isto é, a entrega de um saquinho tanto pode ser a prática caridosa de um devoto quanto a brincadeira para uma criança e ambas podem coexistir junto ao medo causado pela presença de desconhecidos na vila. Além disso, a própria diversão pode ser lida à luz da caridade, assim como a violência que provoca o medo por vezes é uma modalidade de brincadeira. São dimensões de uma festa que se realiza na medida em que relações sociais evitadas ao longo do ano são proporcionadas e permitidas pela extraordinariedade que afeta e revela a configuração da cidade do Rio de Janeiro a cada 27 de setembro.

\section{Um morador pesquisador}


Na festa de Cosme e Damião em 2013, eu integrava o projeto Doces Santos havia apenas dois meses e até então somente um campo exploratório havia sido realizado pelo grupo de pesquisa, no ano anterior. Embora a celebração do dia 27 de setembro perpasse múltiplos espaços - templos, mercados, casas etc - a rua é um locus fundamental pelo qual a festa é vivida e percebida na cidade do Rio de Janeiro. As ruas recebem milhares de pessoas em trajetos atípicos percorridos em busca dos doces e tais deslocamentos são uma das características mais significativas da festa, assim como as casas onde são feitas as entregas dos saquinhos de doce.

Nesse sentido, o trabalho de campo na festa também deveria ser realizado através desses espaços, acessando diferentes bairros, ruas e casas da cidade em busca dos doces e também dos grupos de crianças e doadores. Aproveitando o rendimento do binômio casa/rua feito até aqui, vale ponderar sobre as dificuldades implicadas na realização de um trabalho de campo do qual boa parte consiste na abordagem a grupos de crianças na rua e a devotos em suas casas. Nessas circunstâncias, o pesquisador é, a princípio, um anônimo em estado liminar e potencialmente perigoso, que pode ser tomado pelo o que não é. O tempo da festa pode reconfigurar um pouco essa lógica e tornar essas abordagens menos ameaçadoras, mas ainda assim acrescenta-se à lista de dificuldades a preocupação que identificamos entre os participantes da festa com possíveis constrangimentos causados na interação com alguns adeptos de religiões protestantes, que condenam a prática ${ }^{15}$. Em nossa abordagem, desviando do comportamento usual dos brincantes da festa, poderíamos ser confundidos com pessoas que não só evitam a festa, mas a atacam. Sabedores dessas dificuldades, adotamos as camisetas do grupo de pesquisa como uniforme de trabalho, as quais, junto do gravador ou do caderno de campo, nos identificavam previamente, estreitando a distância entre nós e os nossos interlocutores, que quase sempre nos credenciavam como jornalistas.

Por outro lado, eu pertenço a uma família que desde sempre festeja São Cosme e São Damião a cada 27 de setembro, sendo uma tradição a distribuição dos doces em nossa casa no Bairrinho, em Vista Alegre. Assim, abriu-se a possibilidade de acompanharmos a festa por dimensões que, se negociadas por outros interlocutores, talvez não nos fossem tão acessíveis em tão pouco tempo. Além disso, tratava-se de uma região da cidade onde o mapeamento feito pela pesquisa apontava como área de grande movimento em torno da festa.

\footnotetext{
${ }^{15}$ Sobre as posições evangélicas em relação aos doces de Cosme e Damião, ver Gomes, 2009.
} 
Moura (2003) relata os desafios que encontrou na realização de seu trabalho de campo em dois condomínios horizontais fechados da cidade de Goiânia, nos quais os discursos em torno do medo e da segurança parecem ainda mais acirrados e institucionalizados do que no Bairrinho. A autora, que realizava sua pesquisa enquanto amiga de um casal que residia naquele lugar, nos fala da dificuldade em acessar o círculo de convivência do condomínio sem ser vizinha ou parente dos que lá moravam. Os obstáculos à sua participação no cotidiano de um espaço tão restrito só foram superados quando a própria pesquisadora se tornou proprietária de um imóvel de outro condomínio, onde passou a residir e seguiu sua investigação, assumindo a dupla condição de moradora e pesquisadora.

Apesar de ser uma situação que se aproxima do meu caso, Moura não era uma nativa, mas uma pesquisadora que passou a residir entre seus interlocutores, os quais também não formavam uma coletividade estabelecida e com algum grau de tradição. Pelo contrário, eram membros de camadas médias urbanas habituados à intimidade e circunscrição dos apartamentos, cujos princípios de privacidade e individualidade eram confrontados com o grau de exposição que a vida no condomínio assumia.

Para mim, pesquisador neófito e nativo, o desafio do campo estava em lidar com um fenômeno que sempre naturalizei e jamais havia problematizado. Meu histórico de participação na festa e de inserção nas redes de familiaridade e vizinhança, tão caras ao lugar em que seria feita a pesquisa, tanto poderiam viabilizar o trabalho de campo quanto dificultar o tão recomendado distanciamento psicológico e social do pesquisador ao observar o familiar (VELHO, 1978).

Sendo reconhecido enquanto um morador da vila e participando do dia 27 de setembro enquanto tal, acompanhei de forma privilegiada diversas práticas em torno da festa. Participei efetivamente da montagem e distribuição dos saquinhos em duas casas no Bairrinho - a dos meus pais e a de uma prima. Também distribuí os doces da minha família às crianças de uma pequena creche da vila, quando fui recebido sem muitos protocolos pelos vizinhos responsáveis da casa e pude interagir sem restrições com as crianças. Além dos meus familiares, pude entrevistar informalmente alguns vizinhos que distribuíram doces naquele dia e, em outras ocasiões, fui recebido em suas casas para conversar sobre a relação dessas pessoas com a festa. Se meu lugar de morador permitia acessar esses devotos sem dificuldades, ao assumir o papel 
de pesquisador pude ouvir relatos que dificilmente eu recolheria se tivéssemos apenas uma conversa corriqueira entre vizinhos.

Um dos aspectos mais importantes em ter acompanhado a festa enquanto morador foi a possibilidade de transitar pelas ruas interna da vila, observando as distribuições e abordando doadores e crianças, sem causar estranhamentos ou receios a essas pessoas. Boa parte das crianças do grupo de moradores eram meus primos e filhos de vizinhos que frequentavam nossa casa. Minha presença junto a esse grupo era vista até de forma positiva pelos seus pais, pois eu os supervisionaria. Os vizinhos que me viam correndo atrás dos doces com as crianças entendiam que eu desempenhava essa função de cuidado e, ao saber que também se tratava de uma pesquisa, passaram a tentar contribuir de alguma forma, dando depoimentos ou mesmo indicando quem iria dar doces naquele ano.

Por outro lado, os grupos de fora também me reconheciam como uma pessoa da vila e a princípio interagiam comigo perguntando se eu iria dar doce ou se eu sabia em qual casa estavam dando doces. Depois, ao abordá-los enquanto pesquisador, vestido com a camisa da pesquisa e munido de câmera e caderno, consegui conversar com alguns meninos na tentativa de compreender como eles viam aquela festa.

Matta (1981) define o trabalho de campo como um rito de passagem, seguindo o já mencionado modelo ternário proposto por Gennep (2013). Aplicando esse modelo à inserção do antropólogo na sociedade investigada, vemos o pesquisador afastar-se de sua sociedade, abandonando também seus preconceitos, para assumir um estado liminar e acessar outro universo de relações ou outra cultura e, posteriormente, regressar à sua sociedade com os aprendizados adquiridos. Nas palavras do autor, enquanto um rito de passagem, o trabalho de campo é:

[...] um exercício que nos faz mudar o ponto de vista e, com isso, alcançar uma nova visão do homem e da sociedade no movimento que nos leva para fora do nosso próprio mundo, mas que acaba por nos trazer mais para dentro dele (MATTA, 1981, p. 153).

No desafio de transformar o familiar em exótico (MATTA, 1978), a dificuldade maior está em fazer esse exercício de distanciamento e relativização ao mesmo tempo em que a realização do trabalho de campo depende do acionamento dos vínculos afetivos em um ambiente bastante familiar ao pesquisador. Se a intimidade com o contexto social investigado permite uma fácil visualização da paisagem social e do mapeamento das relações, as pré-noções 
e estereótipos podem dificultar a identificação dos princípios que ordenam essas relações ou dos "mecanismos conscientes e inconscientes que sustentam - e dão continuidade a determinadas relações e situações" (VELHO, 1978, p. 128).

Talvez este empreendimento tenha sido bem-sucedido na medida em que eu não só tentei relativizar minhas pré-noções, mas principalmente porque me tornei consciente delas durante a realização do trabalho de campo - o que eu notava quando havia descompassos entre as ideias que eu trazia da minha experiência na festa e o que se revelava a cada conversa; ou entre minhas intenções enquanto pesquisador e o tratamento que recebia enquanto nativo. No entanto, não pretendo que as análises apresentadas aqui sobre a festa de Cosme e Damião no Bairrinho sejam imaculadas de imprecisões ou de influências decorrentes da minha posição de morador. Pelo contrário, talvez sua contribuição seja justamente o enredamento entre a familiaridade do pesquisador com a festa, a influência direta desta familiaridade na forma como se deu a observação participante e as análises antropológicas que foram produzidas até onde o meu distanciamento pôde alcançar.

\section{Referências bibliográficas}

BOURDIEU, Pierre. A economia das trocas linguísticas: o que falar quer dizer. São Paulo: Edusp, 2008.

CARVALHO, Augusto da Silva. O culto de S. Cosme e S. Damião em Portugal e no Brasil. História das sociedades médicas portuguesas. Coimbra: Imprensa da Universidade, 1928, I volume, p. 1-64.

CASCUDO, Câmara. Dicionário do Folclore Brasileiro. Rio de Janeiro: Ediouro, 1999.

CAVALCANTI, Maria Laura Viveiros de Castro. O Mundo Invisível: Cosmologia, Sistema Ritual e Noção de Pessoa no Espiritismo. Rio de Janeiro: Zahar, 1983.

DOUGLAS, Mary. Pureza e Perigo. São Paulo: Perspectiva, 2012.

FERNANDES, Nelson da Nobrega. O rapto ideológico da categoria subúrbio: Rio de Janeiro (1858-1945). Rio de Janeiro: UFRJ, 1995.

FRADE, Cascia. Populares festas do Estado do Rio de Janeiro. Rio de Janeiro: Instituto Estadual do Patrimônio Cultural, Divisão de Folclore, 1978. 
FREITAS, Morena B. M. De doces e crianças: a festa de Cosme e Damião no Rio de Janeiro. 2015. Dissertação (Mestrado em Antropologia Social). Programa e Pós-graduação em Antropologia Social, UFRJ, Rio de Janeiro.

GENNEP, Arnold Van. Os ritos de passagem. Petrópolis: Vozes, 2013.

GOMES, Edilaine. Doce de Cosme e Damião: Dar, Receber, ou não? In: Dinâmicas Contemporâneas do Funcionamento Religioso na Sociedade Brasileira. Aparecida: Ideias e Letras, 2009, p. 167-185.

LANDES, Ruth. A Cidade das Mulheres. Rio de Janeiro: Editora UFRJ, 2002.

LEACH, Edmund. Anthropological Aspects of Language: Animal Categories and Verbal Abuse. In: LENNEBER, E. H. (ed.). New Directions of the Study of Language. Cambridge: The MIT Press, 1964, p. 22-63.

LIMA, Vivaldo da Costa. Cosme e Damião: O culto dos santos Gêmeos no Brasil e na África. Salvador: Corrupio, 2004.

LOPES, Nei. Dicionário da hinterlândia carioca: Antigos "subúrbio" e "zona rural". Rio de Janeiro: Palas, 2012.

MATTA, Roberto Da. O Ofício de Etnólogo, ou como ter 'Anthropological Blues. In: NUNES, Edson de Oliveira (org.). A Aventura Sociológica. Rio de Janeiro: Zahar Editores, 1978, p. 23-35.

1981.

Relativizando: Uma introdução à antropologia social. Petrópolis: Vozes, . A casa \& a Rua. Rio de Janeiro: Rocco, 1997a.

Carnavais, malandros e heróis: para uma sociologia do dilema brasileiro.

Rio de Janeiro: Rocco, 1997b.

MELlo, Marco Antonio da Silva, VOGEL, Arno. Quando a Rua Vira Casa: A Apropriação de Espaços de Uso Coletivo em um Centro de Bairro. São Paulo: FINEP/IBAM, 1981.

. Lições da Rua: O Que um Racionalista Pode Aprender no Catumbi.

Arquitetura Revista, v. 1, n.1, p. 67-79, 1983.

MENEZES, Renata de Castro. Doces santos: reciprocidade, relações interreligiosas e fluxos urbanos em torno à devoção a Cosme e Damião no Rio de Janeiro. Rio de Janeiro: Museu Nacional / UFRJ, 2013. 
Doces santos: sobre os Saquinhos de Cosme e Damião. In: GOMES, Edlaine; LINS, Paola (Org.). Patrimônio Religioso no estado do Rio de Janeiro. Rio de Janeiro: Coleção Trama de Ideias, 2016, p. 1-23.

MOURA, Cristina Patriota. Vivendo entre muros: o sonho de aldeia. In: Gilberto Velho e Karina Kuschnir (org.) Pesquisas urbanas: desafios do trabalho antropológico. Rio de Janeiro: ZAHAR, 2003, p. 43-54.

SILVA, Maria Lais Pereira da. A favelas e o subúrbios: associações e dissociações na expansão suburbana da favela. In: OLIVEIRA, Márcio Piñon de; FERNANDES, Nelson da Nóbrega. (Org.). 150 Anos de Subúrbio Carioca. Rio de Janeiro, Niterói: Lamparina Editora, Editora da UFF, 2010, p. 161-186.

TURNER, Victor. O processo ritual: estrutura e antiestrutura. Rio de Janeiro: Vozes, 1974.

VELHO, Gilberto. Observando o familiar. In: NUNES, Edson (org.). A Aventura sociológica: Objetividade, paixão, improviso e método na pesquisa social. Rio de Janeiro: Zahar. 1978, p. 121-132.

VELLOSO, Mônica Pimenta. As tias baianas tomam conta do pedaço: Espaço e identidade cultural no Rio de Janeiro. Estudos Históricos, vol. 3, n. 6, p. 207-228, 1990.

Recebido em: Maio de 2018

Aprovado em: Julho de 2018 